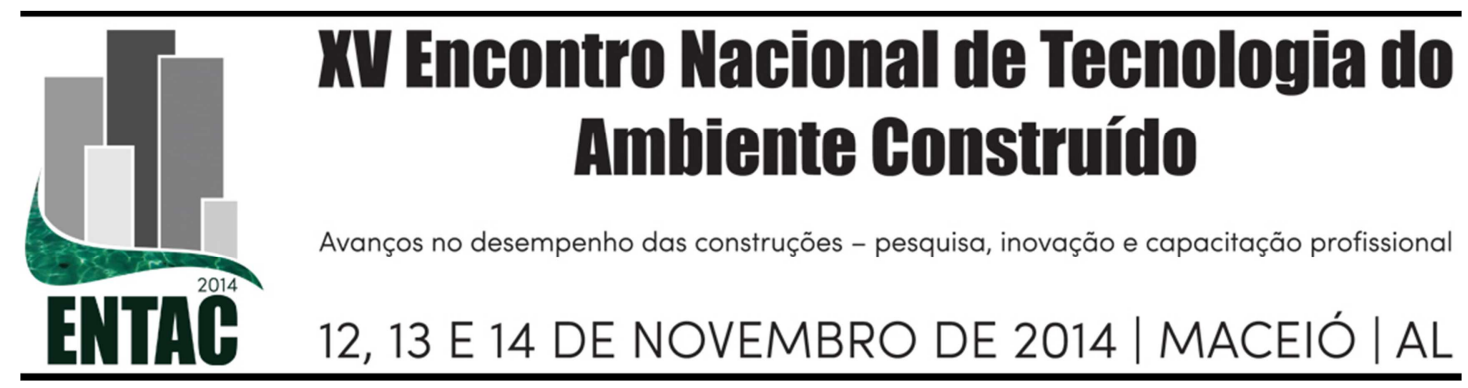

\title{
AVALIAÇÃO DE DESEMPENHO TÉRMICO DE PACKING HOUSES DE FRUTAS NO SEMIÁRIDO NORDESTINO
}

\author{
DACANAL, Cristiane (1); TURCO, Silvia Helena Nogueira (2); LUZ, Simone do \\ Nascimento (3); VASCONCELOS, Osvaldo Campelo de Mello (4)
}

(1) Universidade Federal do Vale do São Francisco (UNIVASF), cris_arquiteta@yahoo.com.br (2)UNIVASF, silvia.turco@univasf.edu.br (3) UNIVASF, simone_nluz@yahoo.com.br (4)

UNIVASF, eng.osvaldocampelo@hotmail.com

\begin{abstract}
RESUMO
O Vale do Submédio São Francisco, especialmente o pólo de Petrolina-PE e Juazeiro-BA, tem se destacado mundialmente na fruticultura, sendo grande responsável pelo abastecimento do mercado interno e externo. Apesar do Clima Tropical Semiárido, associado à irrigação, favorecer a produtividade agrícola durante todo o ano, altas temperaturas e baixa umidade relativa do ar não são adequadas para o armazenamento dos frutos nem tanto ao conforto térmico dos trabalhadores. Diante disso, este trabalho em desenvolvimento tem como objetivo caracterizar o microclima o conforto térmico de trabalhadores de uma packing house de uvas de pequeno porte, não climatizada, no período de inverno. Foram coletados dados de temperatura do ar, umidade relativa do ar, temperatura de globo negro, e velocidade do ar, na altura de $1,5 \mathrm{~m}$ e registrados a cada quinze minutos ao longo de quatro dias. O PMV foi calculado no RayMan para diferentes trabalhadores. Os resultados mostram desconforto térmico durante toda a jornada, com PMV entre 1 e 4,5. A ventilação da edificação por meio de longarina não teve eficácia no período de inverno. Os materiais metálicos (cobertura e portões) e o ambiente externo (chão de terra batida) são altamente responsáveis pelo ganho térmico da edificação, e apresentaram temperaturas superficiais de $\sim 36{ }^{\circ} \mathrm{C}$. O estudo deverá ser ampliado com aplicação de questionários para avaliação de preferencia térmica e novos monitoramentos no período de verão.
\end{abstract}

Palavras-chave: Conforto Térmico Industrial, Arquitetura Bioclimática, Desempenho Térmico.

\begin{abstract}
Sao Francisco Valley, located in Brazilian Northeast, especially Petrolina City and Juazeiro City, have an important role in fruit production in worldwide, supplying fresh fruits to the domestic and foreign markets. Despite the Semi-Arid Tropical Climate promotes a good productivity in the irrigated agriculture throughout the year, high air temperatures and low relative humidity are not suitable for fresh fruits storage nor to the human thermal comfort. Thus, the aims of this work are to characterize the microclimate and the workers thermal comfort in a small grapes' packing house. Air temperature, relative humidity, black globe temperature and air velocity were monitored at 1.5 height for four days at a 15 minutes. PMV was calculated in RayMan model, considering the workers' activities. Results show thermal discomfort throughout the day since PMV varies between 1 and 4.5 . Ventilation of the building through the stringer was not effective during the winter. Metallic materials (in the cover and the gates) and the external environment (dirt and dry soil) are highly responsible for the heat gain of the building, and presented surface temperatures of $\sim 36^{\circ} \mathrm{C}$. The study will be expanded, assessing thermal preference with questionnaires and doing new monitoring campaigns in the summer.
\end{abstract}

Keywords: Industrial Thermal Comfort, Bioclimatic Architecture, Thermal performance. 


\section{INTRODUÇÃ̃O}

A região do Vale do Submédio São Fancisco, localizada no Nordeste brasileiro, tem seu desenvolvimento voltado à fruticultura irrigada, abastecendo o mercado interno $\mathrm{e}$ externo, destacando-se o polo produtor de Petrolina-PE e Juazeiro-BA. Está sob a influência do Clima Tropical Semiárido, que apesar de ser favorável a produção agrícola, não é adequado para armazenamento de frutos e vegetais frescos.

Nestas cidades estão instaladas unidades de beneficiamento, denominadas packing houses, locais em que os frutos são recebidos, selecionados, limpos, tratados, embalados, armazenados e em seguida transportados ao mercado consumidor.

As packing houses são caracterizadas por galpões com vãos amplos, construídos em estrutura metálica ou em concreto, vedados em alvenaria e com coberturas leves (telhas de fibrocimento ou metálica). Os materiais de vedação, especialmente paredes externas e cobertura, são altamente responsáveis pelo ganho térmico no interior, por apresentarem alto coeficiente calorífico, incrementando a carga térmica da edificação no período diurno. Os sistemas de condicionamento de ar e as câmaras frias de armazenamento geralmente se restringem aos grandes produtores, que abastecem o mercado externo, por requererem alto custo de implantação e de manutenção. A grande maioria das packing houses desta região são galpões simples, sem sistemas de refrigeração.

O ambiente térmico no interior das packing houses afeta tanto a qualidade dos frutos, na etapa pós-colheita, quanto a produtividade do trabalhador, que pode diminuir em condições de desconforto térmico.

As condições higrotérmicas ideais de armazenamento, para a maioria dos frutos, são de temperatura do ar amena e umidade relativa elevada. Para a uva, um dos principais frutos produzidos em Petrolina, as condições adequadas de armazenamento são temperatura do ar de $0{ }^{\circ} \mathrm{C}$ e umidade relativa do ar acima de $90 \%$. Sob temperaturas elevadas, ocorre o aumento da atividade metabólica dos frutos, reduzindo sua qualidade de consumo (BRACKMANN et al., 2000).

Por outro lado, os trabalhadores do semiárido nordestino estão adaptados ao clima quente e seco, e sentem desconforto por frio, em ambientes com ar condicionado, ou por calor, sob estruturas com baixo isolamento térmico. Ressalta-se que muitos dos trabalhadores do campo, também trabalham em packing houses na época da colheita. No setor de embalamento dos frutos, cujo ambiente está aclimatado entre $20-25^{\circ} \mathrm{C}$, os funcionários geralmente queixam-se de frio e adoecem com facilidade, relatam os produtores. Fica evidente o motivo deste desconforto quanto se observam temperaturas médias máximas mensais superiores a $30{ }^{\circ} \mathrm{C}$.

Atendendo a demanda dos pequenos produtores, que são uma maioria no Vale do Submédio São Francisco, é recomendável a adequação do projeto arquitetônico das packing houses ao clima local, a fim de mitigar o desconforto térmico dos trabalhadores e criar condições térmicas para minimizar as perdas de qualidade dos frutos na póscolheita.

Dessa maneira faz-se necessário um diagnóstico de desempenho térmico das unidades de beneficiamento de frutos no Vale do Submédio São Francisco, tendo em vista a importância deste setor para a economia local e nacional. 


\section{OBJETIVO}

Caracterizar o microclima o conforto térmico de trabalhadores de uma packing house de uvas de pequeno porte, não climatizada, localizada no Vale do Submédio São Francisco, no período de inverno.

\section{APRESENTAÇÃO DOS LOCAIS DE ESTUDO}

\subsection{Clima de Petrolina}

O clima da região é Tropical Semiárido (BSwh - de acordo com a classificação de Köeppen-Geiger), seco e muito quente, com máxima precipitação em março e mínima em agosto. Segundo Brito et al (2007, p. 37), o Semiárido brasileiro é formado por "um conjunto de espaços que se caracterizam pelo balanço hídrico negativo, resultante de precipitações médias anuais inferiores a $800 \mathrm{~mm}$, insolação média de $2800 \mathrm{~h}$ ano-1, temperaturas médias anuais de $23^{\circ}$ a $27^{\circ} \mathrm{C}$, evaporação de $2.000 \mathrm{~mm}$ ano e umidade relativa do ar média em torno de 50\%."

O Quadro 1 apresenta valores médios mensais e anual da umidade relativa do ar (UR, $\%$ ), temperatura do ar média (T Med, ${ }^{\circ} \mathrm{C}$ ), máxima (T Máx, ${ }^{\circ} \mathrm{C}$ ) e mínima (T Mín, ${ }^{\circ} \mathrm{C}$ ) e totais mensais e anuais da evaporação do tanque Classe A (E, mm) e da precipitação $(\mathrm{P}$, $\mathrm{mm}$ ), observados na Estação Meteorológica de Bebedouro (0909'S; 40²2'O; 365,5m), localizada em Petrolina - PE, no período de 1965 a 2005.

Quadro 1 - Normais Climatológicas de Petrolina-PE

\begin{tabular}{|c|c|c|c|c|c|c|}
\hline Meses & $\begin{array}{c}\text { UR } \\
(\boldsymbol{\%})\end{array}$ & $\begin{array}{c}\text { T Med } \\
\left({ }^{\mathbf{}} \mathbf{C}\right)\end{array}$ & $\begin{array}{c}\text { T Max } \\
\left({ }^{\mathbf{}} \mathbf{C}\right)\end{array}$ & $\begin{array}{c}\text { T Min } \\
\left({ }^{\mathbf{}} \mathbf{C}\right)\end{array}$ & $\begin{array}{c}\mathbf{E} \\
(\mathbf{m m})\end{array}$ & $\begin{array}{c}\mathbf{P} \\
(\mathbf{m m})\end{array}$ \\
\hline Janeiro & 67,1 & 26,9 & 32,5 & 21,5 & 221,6 & 87,0 \\
\hline Fevereiro & 68,0 & 26,8 & 32,4 & 21,6 & 192,9 & 80,4 \\
\hline Março & 71,4 & 26,4 & 31,9 & 21,5 & 196,2 & 133,7 \\
\hline Abril & 72,6 & 26,2 & 31,4 & 21,1 & 181,4 & 79,9 \\
\hline Maio & 69,9 & 25,5 & 30,8 & 20,1 & 182,1 & 21,0 \\
\hline Junho & 68,7 & 24,5 & 29,9 & 18,8 & 176,5 & 12,2 \\
\hline Julho & 66,0 & 24,1 & 29,6 & 18,1 & 200,1 & 8,1 \\
\hline Agosto & 60,8 & 24,9 & 30,9 & 18,4 & 244,2 & 4,0 \\
\hline Setembro & 56,8 & 26,5 & 32,7 & 19,8 & 266,3 & 4,9 \\
\hline Outubro & 54,4 & 27,9 & 34,0 & 21,2 & 298,7 & 10,1 \\
\hline Novembro & 57,7 & 28,1 & 33,9 & 22,0 & 263,8 & 47,2 \\
\hline Dezembro & 63,1 & 27,5 & 33,2 & 21,8 & 235,2 & 71,6 \\
\hline Anual & 64,7 & 26,3 & 31,9 & 20,5 & 2659,0 & 557,7 \\
\hline
\end{tabular}

Fonte: (BRITO et al, 2007) 
Distinguem-se dois períodos típicos ao longo do ano, verão e inverno, com temperaturas mínimas no mês de julho. As chuvas concentram-se no verão, sendo março o mês de maior pluviosidade. Os ventos predominam na direção sudeste (Azimute aproximado de $\left.100^{\circ}\right)$.

Em termos de conforto térmico, os meses de setembro, outubro e novembro são considerados muito quentes, pois o longo período de estiagem combinado à elevada temperatura do ar, acarreta o balanço hídrico negativo e umidades relativas do ar inferiores a $50 \%$, podendo chegar a extremos, como registrado UR $=10,1 \% \mathrm{em}$ setembro de 2013.

\subsection{Packing House de Uvas}

A packing house avaliada neste trabalho é de pequeno porte e não climatizada. Denomina-se Salva Terra e localiza-se na Zona Rural no Núcleo Agrícola N-8, ( $9^{\circ} 17^{\text {' }}$ $31,5^{\prime \prime} \mathrm{Sul} ; 40^{\circ} 28^{\prime}$ 57,8" Oeste), em Petrolina-PE.

Nesta unidade, as uvas são colhidas, selecionadas, pesadas, embaladas e expedidas (Figura 1) para um grande produtor, responsável pelo acondicionamento dos frutos em câmaras frias e comercialização para o mercado interno e externo.

A estrutura da packing house é em concreto armado, vedação em alvenaria com pintura externa em amarelo e revestimento interno até aproximadamente dois metros em cerâmica branca, portas em aço, cobertura em arco com telhas em aço galvanizado, janelas do escritório em madeira e vidro, piso em granilite, longarina telada com altura de um metro na face sudeste. Existem barreiras de vegetação (cercas-vivas) próximas às laterais sudeste e noroeste da edificação (Figura 1). 


\section{Figura 1 - Planta e Layout da Linha de produção da Packing House Salva Terra}

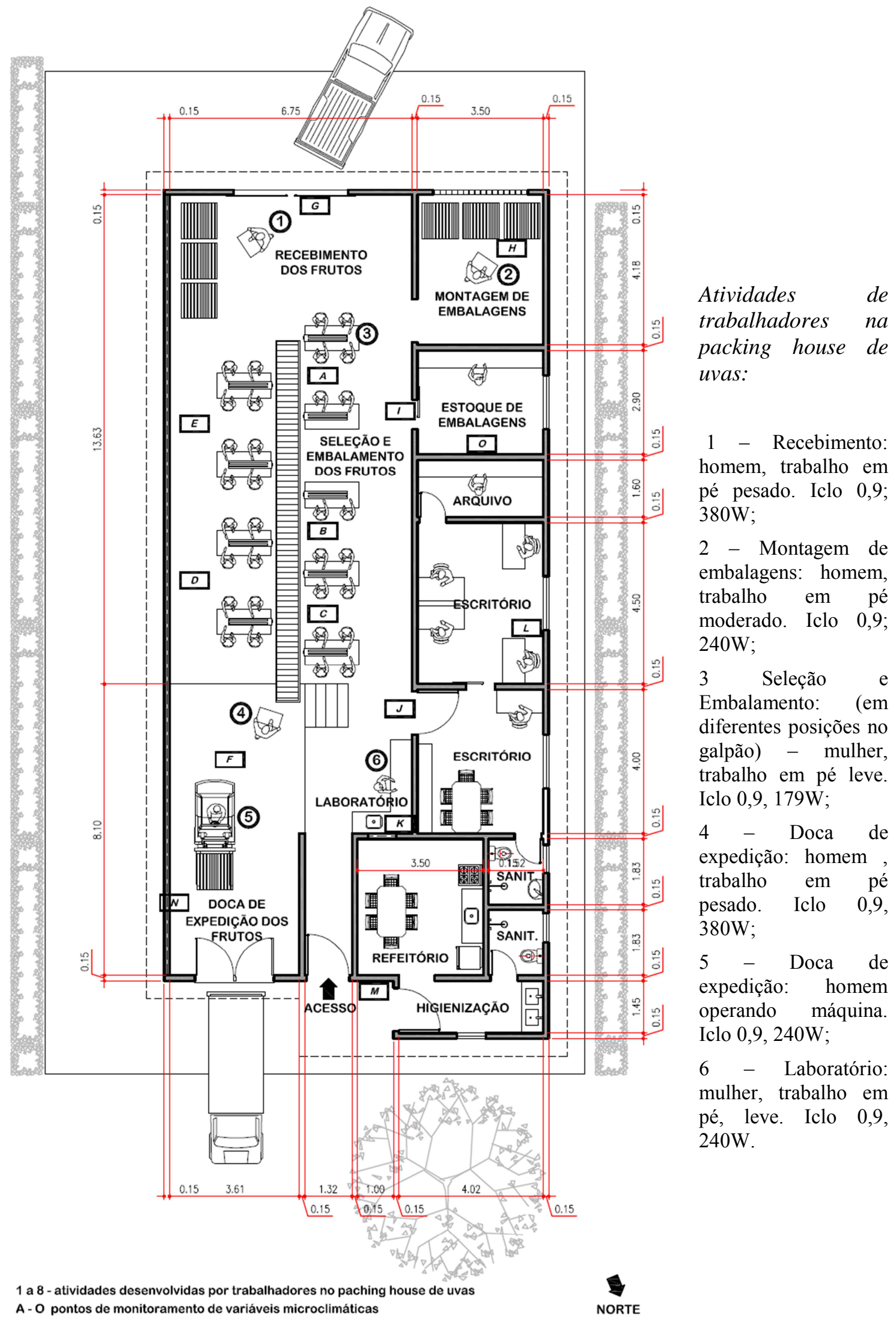




\section{METODOLOGIA}

Dados microclimáticos (temperatura do ar, umidade relativa do ar, temperatura de globo negro e velocidade do ar) foram registrados em 15 pontos distribuídos no interior da packing house, nos diversos setores da linha de beneficiamento, conforme indicado na Figura 1. Os critérios utilizados para a localização dos pontos de medição foram a proximidade dos sensores aos trabalhadores, com uma distância máxima de 2,0 m, e a desobstrução do espaço físico, para que não afetasse as atividades de trabalho. Para isso, os sensores foram fixados em estruturas metálicas presentes no galpão, e não em tripés como se faz usualmente. Os registros de temperatura e umidade foram feitos automaticamente a cada 15 minutos, na altura de 1,5 metros, no período de 13/05/2014 a 17/05/2014. O tempo estava parcialmente nublado com temperatura amena para as condições locais, caracterizando o período de inverno. A velocidade do ar interno foi feita ao longo de uma jornada de trabalho, a cada hora. As medidas foram feitas com portas abertas e fechadas, ventiladores ligados e desligados.

Foram tomadas fotografias térmicas do interior e exterior da edificação para a estimativa da temperatura superficial dos componentes construtivos, identificando-se as principais fontes de calor radiante.

Os instrumentos utilizados foram:

- $\quad$ Sensores de temperatura do ar e umidade relativa do ar, Hobo H12, com canal externo onde foi acoplado um termopar inserido em um globo negro;

- Câmera fotográfica Flir, Modelo 420, para imagens térmicas e estimativas das temperaturas superficiais;

- Termo-anemômetro digital portátil TAVR-650 Instrutherm, para velocidade do ar.

Foram gerados gráficos das variáveis microclimáticas ao longo do tempo (médias horárias dos dias). O PMV - Voto Médio Estimado (ISO 7730/94) - dos trabalhadores na linha de produção, localizados nos pontos de 1 a 6 na Figura 2, foi calculado no Ray Man 1.2, baseando-se nos dados microclimáticos e cálculo da TMR a partir da temperatura de globo, temperatura do ar e velocidade média do ar; na atividade de trabalho e estimativa da taxa metabólica (MET com conversão para W, a partir da estimativa da área corporal do individuo); e nas vestimentas dos trabalhadores (Iclo). $\mathrm{O}$ cálculo foi feito para os seguintes indivíduos padrão:

- homem (20 anos, $70 \mathrm{~kg}, 1,70 \mathrm{~m})$, I clo = 0,9, para atividade moderada em pé, atividade pesada em pé, atividade leve sentado.

- mulher (20 anos, $60 \mathrm{~kg}, 1,60 \mathrm{~m})$, I clo =0,9, para atividade leve em pé, atividade moderada em pé, atividade leve sentado.

\section{APRESENTAÇÃO DOS RESULTADOS}

\subsection{Microclima}

A Figura 2 mostra o comportamento térmico nos 15 pontos monitorados. A temperatura máxima média obtida no galpão foi de $29,5{ }^{\circ} \mathrm{C}$, a mínima média de $24,4{ }^{\circ} \mathrm{C}$ e a média absoluta de $26,6{ }^{\circ} \mathrm{C}$. A umidade relativa média absoluta foi de $67 \%$, a máxima média $78 \%$, no período da manhã, e a mínima média 55\%. Estes valores são comparáveis aos das normais climatológicas para o mês de maio (Quadro 1), em que o monitoramento foi realizado. 
Figura 2 - Média horária da temperatura do ar e umidade relativa do ar na Packing House avaliada
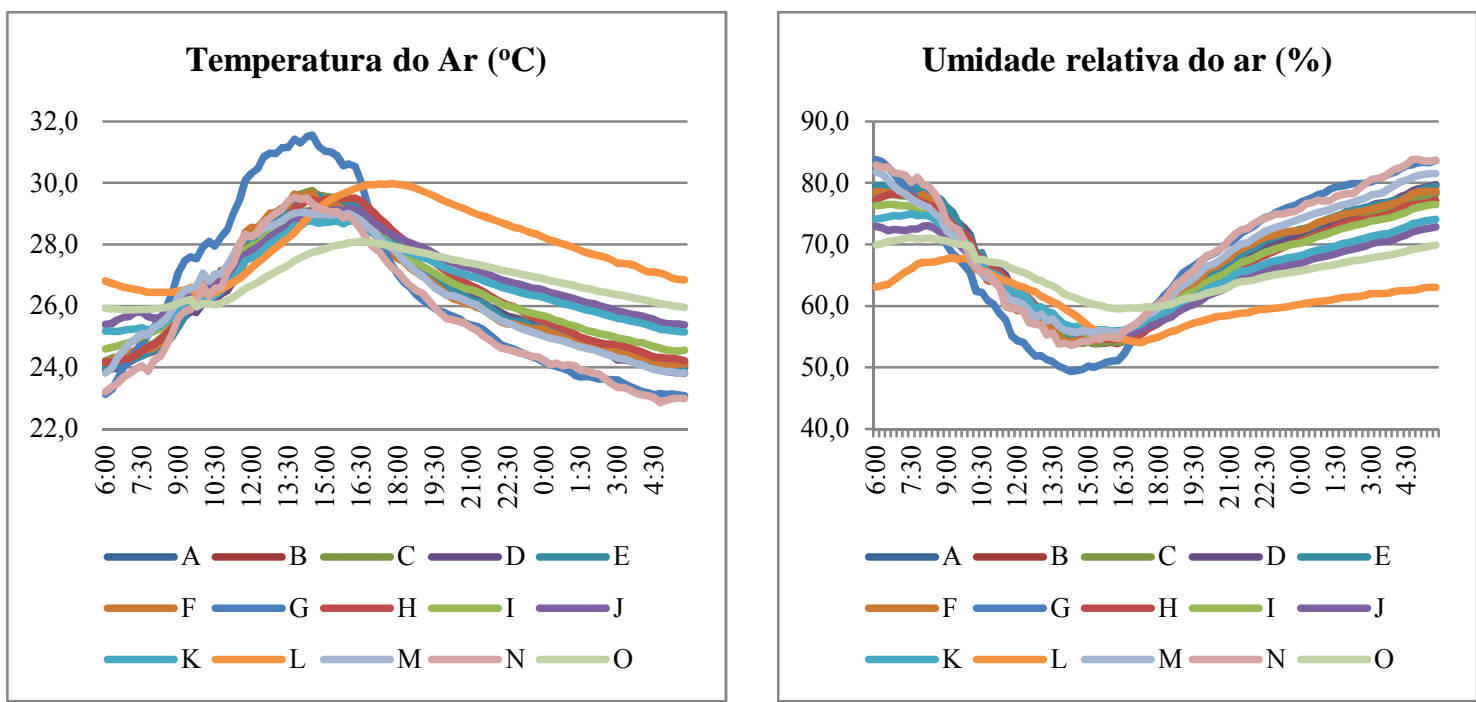

Pontos de Medição nomeados de "A" a "N", conforme posição no galpão indicada na Figura 1.

É evidente a variação térmica dos ambientes, influenciados pela emissão de calor radiante do aço presente na cobertura e portões. Verificou-se maior aquecimento e maior amplitude térmica no ponto $G$ localizado junto ao portão de aço na área de recebimento de frutos, com temperatura máxima de $31,4{ }^{\circ} \mathrm{C}$ às $13: 45 \mathrm{~h}$. $\mathrm{O}$ ponto $\mathrm{L}$, no interior do escritório, apresentou temperaturas mais elevadas, com máxima de $30{ }^{\circ} \mathrm{C}$, que a maioria dos pontos ao longo do dia, e baixa amplitude térmica.

Como a temperatura interna no galpão assemelha-se à temperatura externa, a perda de calor por ventilação é mínima ou inexistente. Verificou-se que a temperatura do ar na longarina, ponto $\mathrm{N}$, encontrava-se menos elevada que a maioria dos pontos, e com baixa amplitude térmica ao longo do dia. Portanto, não houve trocas térmicas por efeito chaminé.

A ventilação nos arredores da edificação esteve diminuída pela presença das cercas vivas nas laterais, que formam uma zona de baixa pressão, com medidas de velocidade do ar inferiores à $1 \mathrm{~m} / \mathrm{s}$. O efeito térmico das cercas vivas na edificação não foram monitorados, porém sua presença pode beneficiar a edificação pelo sombreamento, como pode dificultar as trocas térmicas convectivas entre a superfície das paredes. Como o vento predominante é SE, a própria edificação faz uma barreira na face $\mathrm{NO}$, em contato com a área agrícola (parreiral de uvas).

As fotografias térmicas (Figura 3 ) mostram temperaturas superficiais elevadas $\left(\sim 36{ }^{\circ} \mathrm{C}\right)$ nos materiais metálicos - telhas e portões - e do chão de terra batida, que interferem no ganho de calor da edificação. Assim, as faces NE e SO (Figura 3 a-b; e-f) apresentaram-se aquecidas, devido a presença de portões metálicos. 
Figura 3 - Fotografias e Imagens Térmicas da Packing House avaliada

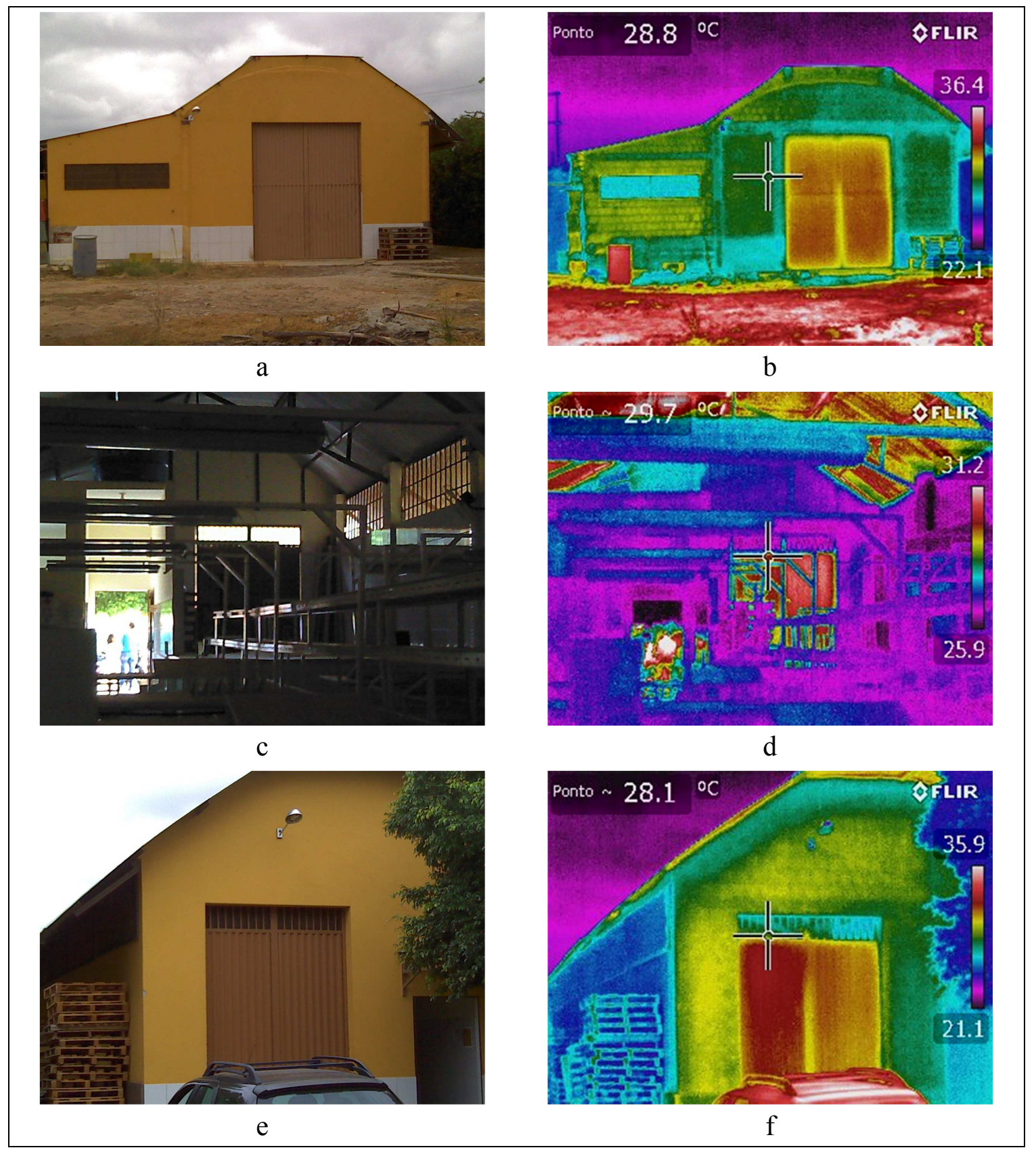

Fotos tiradas em 17/05/2014 às 10:00h, em condições de tempo nublado e temperatura amena.

\subsection{Conforto térmico dos trabalhadores}

Verificou-se o desconforto térmico dos trabalhadores por calor em toda a linha de produção, de dia e a noite, com PMV superiores a 1 (Figura 4). O desconforto é afetado especialmente pela atividade de trabalho, sendo que as atividades pesadas de levantar caixas na plataforma de recebimento e na doca de expedição as mais estressantes, com PMV superior a 3 pontos em qualquer turno de trabalho. Os locais em que estas duas atividades são desenvolvidas são próximos aos portões de aço, encontram-se abertos no momento do recebimento e da expedição, sofrendo influencia da radiação solar direta em certos períodos. 
Já nas mesas de classificação e embalagem dos frutos, onde se concentra a maioria dos funcionários, o PMV indicou desconforto leve a moderado por calor, assim como o trabalho de controle de qualidade, realizado no laboratório. A montagem de embalagens indicou PMV entre 2 e 3 , valor intermediário entre as outras atividades citadas.

Figura 4 - Voto Médio Estimado de trabalhadores da Packing House avaliada

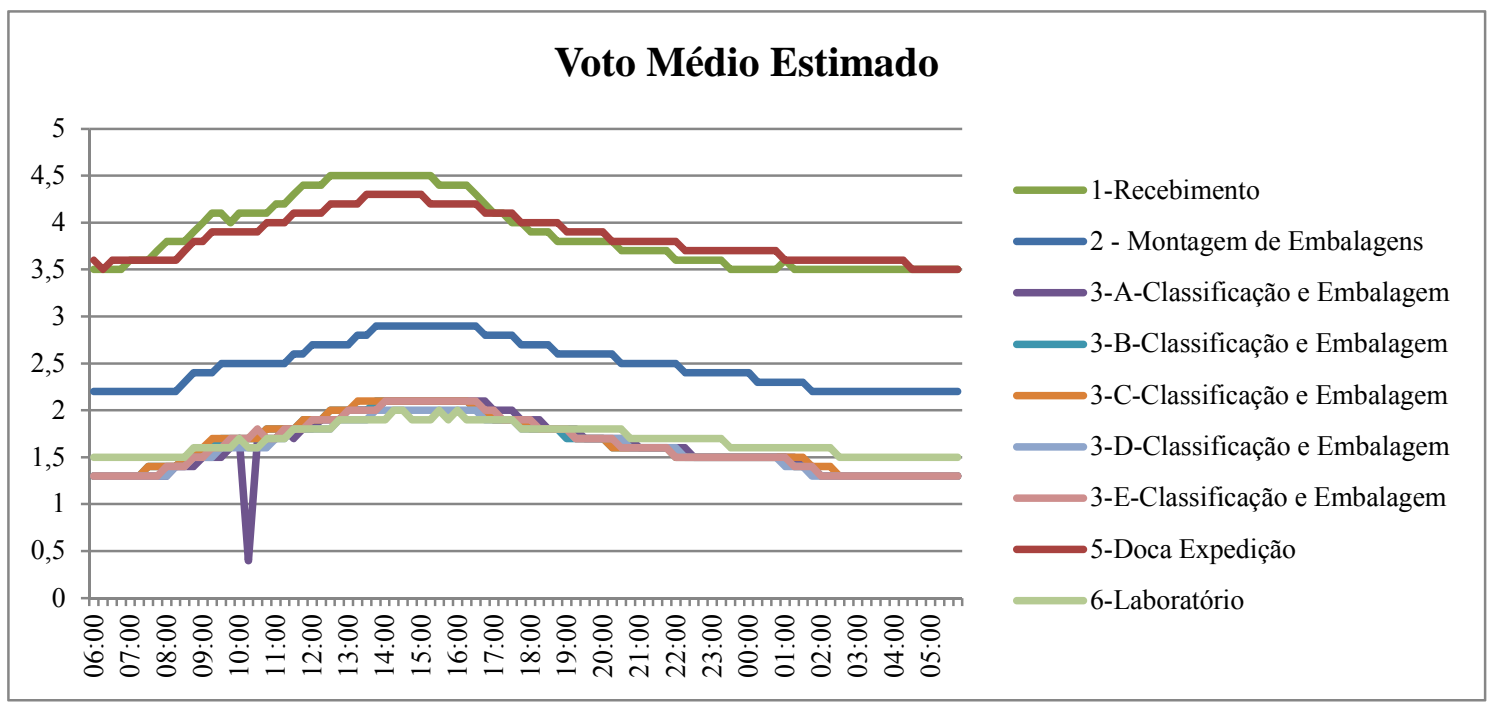

\section{DISCUSSÃO}

Petrolina apresenta importantes oscilações nos valores da umidade relativa e da temperatura do ar, distintas entre o período de verão e inverno, as prescrições de estratégias bioclimáticas distinguem-se entre as estações climáticas, especialmente quanto ao uso da ventilação natural, que deve ser evitada em períodos quentes. Já o uso da alta inércia térmica associada ao resfriamento evaporativo aparece de forma mais uniforme como recomendação válida para o ano (Martins et al, 2012; NBR 15220).

Esta primeira etapa de realização da pesquisa correspondeu ao período de inverno. Neste caso, recomenda-se a ventilação natural (cruzada) em certos horários do dia, a perda de calor por convecção em aberturas localizadas junto a cobertura, o sombreamento e o emprego de materiais construtivos isolantes e com alta inércia térmica. No entanto, verifica-se nem todas as estratégias foram consideradas no momento do projeto da edificação.

Esperava-se o efeito chaminé da packing house avaliada através da longarina, que não teve eficiência devido às condições climáticas em que o monitoramento foi realizado. A longarina encontra-se numa posição que funciona como captador de ventos, e se a temperatura exterior for menor ou igual à interna não ocorre o esperado efeito chaminé. Neste caso, o uso de lanternim ou exaustores na cobertura seria uma opção mais eficiente, já que a cobertura em aço apresenta-se muito aquecida no período diurno.

O uso de ventiladores no interior do galpão pode melhorar as condições de conforto, mas não beneficiam, neste caso, a diminuição da temperatura do ar interno .

Em relação ao sombreamento, são necessários estudos de insolação e o dimensionamento de para-sois (beirais, marquises e cercas-vivas), para evitar a insolação direta nas paredes e portões metálicos. As estruturas de sombreamento devem ser avaliadas juntamente com estudos de ventilação. No caso do clima tropical 
semiárido, o sombreamento é mais eficaz que a ventilação cruzada, portanto deve ser priorizado.

A substituição de telhas de aço galvanizado por telhas com maior isolamento e de cores claras minimizaria o ganho de calor da edificação. Aconselha-se o uso de telhas termoacústicas brancas.

O desconforto térmico dos funcionários seria melhorado com a climatização do ambiente e com o emprego das estratégias bioclimáticas citadas, já que as vestimentas não podem ser alteradas devido às exigências sanitárias.

\section{CONSIDERAÇÕES FINAIS}

A packing house de uvas avaliada apresenta desempenho térmico insatisfatório, avaliado a partir do PMV calculado para os trabalhadores na linha de produção. O emprego de estratégias bioclimáticas de projeto recomendadas para o Clima Tropical Semiárido, tais como o sombreamento, o uso de materiais isolantes e com baixa emissividade, e chaminés para maximizar as trocas térmicas convectivas, melhorariam o microclima interno, e consequentemente o conforto térmico e uma ambiência mais adequada para o acondicionamento das uvas, que exigem temperatura amena e umidade relativa elevada.

A investigação das condições de conforto devera ser ampliada, com a aplicação de questionário para verificação do desconforto e preferencia térmica dos funcionários, adaptados ao clima quente. Para as condições de verão, novos monitoramentos deverão ser efetuados com sugestões para a melhoria do desempenho térmico desta edificação.

\section{AGRADECIMENTOS}

À CAPES, pela bolsa PNPD do autor 1 .

\section{REFERÊNCIAS}

ASSOCIAÇÃO BRASILEIRA DE NORMAS TÉCNICAS (ABNT). NBR-15220-3: Desempenho térmico de edificações. Parte 3: Zoneamento bioclimático brasileiro e diretrizes construtivas para unifamiliares de interesse social. Rio de Janeiro, 2005.

BACHMANN, J.; EARLES, Richard, 2000. Postharvest handling of fruits and vegetables. ATTRA - Appropriate Technology Transfer for Rural Areas, Horticulture Technical Note, August, 2000. Disponível em: http://www.attra.org/attrapub/postharvest.html. Acesso em Out.2013.

BRITO, L.T.L (Org.) ; MOURA, M. S. B. (Org.) ; Gama, G. F. B. (Org.) . Potencialidades da água de chuva no Semi-Árido brasileiro. 1. ed. Petrolina: Embrapa Semi-Árido, 2007. v. 1. $179 \mathrm{p}$.

INTERNATIONAL ORGANIZATION FOR STANDARDIZATION. ISO 7730: Moderate thermal environments - Determination of the PMV and PPD indices and specification of the condictions for termal comfort. 1994.

MARTINS, T.A.L; BITTENCOURT, L.S.;KRAUSE, C.M.L.B. Contribuição ao zoneamento bioclimático brasileiro: reflexões sobre o semiárido nordestino. Ambiente Construído, Porto Alegre, v. 12, n. 2, p. 59-75, abr./jun. 2012. 